DR. RICK STOFFELS (Orcid ID : 0000-0003-4888-5875)

PROF. NICK R BOND (Orcid ID : 0000-0003-4294-6008)

DR. SAM NICOL (Orcid ID : 0000-0002-1160-7444)
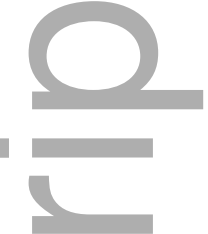

Article type : Special Issue

\title{
Science to support the management of riverine flows
}

Running title: Science for flow management

Rick J. Stoffels ${ }^{*}$, Nick R. Bond ${ }^{\dagger} \&$ Sam Nicol ${ }^{\ddagger}$

* Murray-Darling Freshwater Research Centre, CSIRO Land and Water, Wodonga, VIC, Australia

† Murray-Darling Freshwater Research Centre, La Trobe University, Wodonga, VIC, Australia

FSIRO Land and Water, EcoSciences Precinct, Dutton Park, QLD, Australia

Correspondence: Rick Stoffels, CSIRO Land and Water, PO Box 821, Wodonga, VIC, 3690, Australia. Email: rick.stoffels@csiro.au

Keywords: adaptive management; environmental flows; flow regime; forecasting; river regulation

\section{SUMMARY}

1. The last two decades has seen introduction or reform of water legislation in many river basins of the world, and river managers are under increasing pressure to make effective and efficient flow management decisions. To support those decisions, the roles that freshwater scientists must fulfil are rapidly evolving, and now is a good time to ask: What roles must scientists

This is the author manuscript accepted for publication and has undergone full peer review but has not been through the copyediting, typesetting, pagination and proofreading process, which may lead to differences between this version and the Version of Record. Please cite this article as doi: $10.1111 /$ fwb.13061

This article is protected by copyright. All rights reserved 
fulfil to best support those decisions? What are the major barriers to seeing those roles fulfilled? How can those barriers be removed?

2. We offer potential answers to these questions. To ensure our arguments are grounded within real policy and decision problems, they are framed within the context of Australia's MurrayDarling Basin Plan-legislation to guide the management of environmental flows-and its associated Watering Strategy. These problems are not unique, so the challenges and solutions we identify have broader applicability to flows management. Indeed, many of the policy and decision problems we present are common to all ecosystem types, so our arguments will likely be applicable beyond freshwater ecosystems.

3. We argue that scientists must fulfil four roles to support flows management: (1) Monitoring and evaluation of ecosystems to support scientifically-defensible reporting of outcomes, and to reduce uncertainty through adaptive management. (2) Modelling to support spatial and temporal projections of ecosystem change under different flow scenarios, resulting in more effective management decisions; improved causal inference about flow effects; identification of threats to the efficacy of flow management; and scaling flow-response dynamics to broader spatial extents. (3) Fundamental research, resulting in improved outcomes through the identification of non-flow management interventions that work in synergy with environmental flows; and improved understanding of the ecological limitations of current policy. (4)

Decision science, leading to more defensible environmental flow decisions and more efficient use of resources.

4. We identify key barriers specific to each role and offer possible remedies. We argue that a major impediment to seeing these roles fulfilled is the ad hoc nature of much of the current research effort. Investment in research must: (1) be developed at the basin scale, to ensure science supports decision problems that span multiple scales; (2) be developed as a collaboration between all stakeholders to ensure that science investments remain aligned with decision problems; (3) recognise the need to build and maintain technical capacity within the four roles.

\section{Introduction}

In recent decades most of the world's rivers have experienced increased regulation of flows (Nilsson, Reidy, Dynesius et al., 2005). Reform of water legislation in many river basins of the world has followed, as the impacts of flow regulation on riverine ecosystems became apparent (Naiman, Bunn, Nilsson et al., 2002; Arthington, 2012). Freshwater science has played a pivotal role in guiding water reform and, looking ahead, science must continue to fulfil roles that facilitate management decisions and policy reform into the future. However, the roles that freshwater scientists must fulfil are rapidly evolving, and are moving well beyond the provision of new fundamental knowledge (Poff, Allan, Palmer et al., 2003; Arthington, Naiman, McClain et al., 2010). Indeed, river managers are 
increasingly looking to freshwater science to support effective, efficient and scientifically-defensible flow decisions. Questions then arise: What roles must scientists fulfil to best support those decisions? What are the major barriers to seeing those roles fulfilled? How can those barriers be removed? Given the transformative pressures humanity is placing on the planet, scientists have a social responsibility to periodically re-examine their goals and focus (Lubchenco, 1998). Now is a good time to evaluate the roles that freshwater scientists must fulfil, at this pivotal stage in global water reform (Vorosmarty, Green, Salisbury et al., 2000).

In this paper we argue that freshwater scientists must fulfil four major roles to support effective and efficient flow management: (1) scientifically-defensible monitoring and evaluation of flows; (2) modelling to predict the ecological impacts of variability in flows and other ecological drivers in time and space; (3) fundamental research into flow ecology that complements well-designed monitoring projects; (4) supporting decision-making in a variety of ways, from provision of expert opinion through to assistance in identifying optimal decisions in the face of uncertainty. To ensure our arguments are grounded within real policy and decision problems, we refer to Australia's MurrayDarling Basin (MDB) as a case study. Specifically, the discussion that follows is based on Australia's Basin-Wide Environmental Watering Strategy (hereafter Watering Strategy; MDBA, 2014a)—-the strategy that builds on Australia's Basin Plan to guide managers towards meeting Basin Plan objectives - the broader scientific literature, and our own recent experience with flow monitoring and evaluation programs.

Our paper is divided into three main sections: We first briefly introduce the MDB and relevant water policy frameworks. Second, we present a case for the four scientific roles defined above. Last, we identify what we believe are the dominant barriers to the effective and efficient fulfilment of the four scientific roles. We then offer some solutions for removing those impediments. We argue that the effectiveness and efficiency with which science can contribute to these goals would be greatly enhanced not through more funding per se, but through a carefully devised investment strategy that aims to address the right management problems at the right spatial and temporal scales. We hope that this paper will encourage managers and scientists to reconsider their investment and research priorities, and strengthen their partnership to improve the management of riverine flows.

\section{River flows in the Murray-Darling Basin}

The MDB is Australia's largest river system, spanning 14\% of Australia's surface area and five of its eight states/territories. Although it is ranked within the top 20 river basins of the world for its length and area, it discharges one of the world's smallest volumes of water for its size. Much of the MDB receives very little rainfall which, when coupled with low elevation and the slow-flowing nature of the rivers, results in approximately $94 \%$ of runoff being evaporated. In addition to the generally low 
discharge, the Basin experiences strong episodic droughts, certain of which may last a decade, compounding problems of water availability. To secure water for domestic and agricultural uses, most of the Basin's rivers are now heavily regulated. The Basin is the focus of Australia's irrigated production. Consequently, humans have reduced discharge of the Basin by approximately $75 \%$ on average, and have greatly altered the annual hydrographs of its rivers (Maheshwari, Walker \& McMahon, 1995; McMahon \& Finlayson, 2003). Not surprisingly, these hydrological changes have resulted in strong, obvious detrimental impacts on the state of the Basin's river-floodplain ecosystem (Walker \& Thoms, 1993; Kingsford, 2000; Lake \& Bond, 2007).

The MDB is the focus of one of Australia's largest and most controversial ecological restoration projects in recent history (Hart, 2016). In 2012 a legislative instrument (Basin Plan 2012) came into effect to guide the management of freshwater flows within the river-floodplain ecosystems of the MDB. Under the Basin Plan, flows will be delivered to rivers and their floodplains with the objectives of protecting, restoring and improving the resilience of water-dependent habitats, ecosystem processes and biodiversity (MDBA, 2014a). Approximately 2750 gigalitres of water has been set aside to meet Basin Plan objectives as a result of setting a Sustainable Diversion Limit (SDL) for consumptive use. This is ca. $20 \%$ of the volume previously used for irrigation, basin-wide. Despite the magnitude of the environmental problem, the Basin Plan is one of the most controversial pieces of legislation in Australia's recent history (http://theconversation.com/au/topics/murray-darling-351), because competition between the environment and other end-users for the Basin's scarce water is so intense.

The MDB is what some may refer to as a 'novel ecosystem' (Hobbs, Higgs \& Harris, 2009). It has been transformed from its natural state by humans, with the new socio-ecological system providing a suite of services to humans, while also providing habitat to a diverse assemblage of water-dependent flora and fauna (Colloff, Lavorel, Wise et al., 2016). The Basin Plan is not about restoring the MDB to a pre-regulation state, but about managing water to 'support productive industries, farmers and communities into the future, while leaving sufficient water in the Basin's river system to ensure a healthy environment' (MDBA, 2014a). The flow management problem within the MDB is generally not one of delivering natural flow regimes (sensu Arthington, Bunn, Poff et al., 2006; Poff, Richter, Arthington et al., 2010), but to optimise flow management to achieve specific ecological objectives, within the heavy constraints of water availability and delivery (sensu Acreman, Arthington, Colloff et al., 2014). Those objectives centre on maintaining and/or restoring critical ecosystem processes (e.g. sufficient flow to flush salt from the lower reaches) and ecological conditions that multiple stakeholders value (e.g. productive recreational fisheries). In the next section of this paper we argue that scientists must fulfil four roles if we are to meet the management objectives of the Basin Plan.

\section{Role 1: Monitoring and evaluation}


Monitoring projects that are well designed and implemented form a cornerstone of natural resource management (Conroy \& Petersen, 2013; Schindler \& Hilborn, 2015). Within this paper we differentiate the roles of monitoring (Role 1) and fundamental research (Role 3), so a working definition of monitoring is required. We define monitoring as any form of research aimed specifically at inferring the effect(s) of a management intervention on an ecological process or state. We offer a definition of fundamental research below in Role 3: Fundamental research. Note that, based on this definition of monitoring, long-term ecological research is not necessarily monitoring (the converse is also true). In the context of flow management, monitoring is essential for two major reasons: 'reporting' and 'reducing uncertainty' (Fig. 1).

\section{Reporting}

Monitoring and evaluation of managed flows is necessary if we are to provide evidence to consumer, political and economic stakeholders (Table 1) that the objectives underlying flow management are being met, and that environmental water is both necessary and being managed effectively (Bernhardt, Palmer, Allan et al., 2005). Given the intensifying competition for freshwater (Vorosmarty et al., 2000; Colloff et al., 2016), scientists, managers and NGOs (Table 1) are unlikely to demonstrate that current water allocations to riverine ecosystems are required if we cannot provide strong evidence for their ecological value.

\section{Reducing uncertainty}

Monitoring and evaluation of environmental flows is necessary to reduce uncertainty about how flow management affects ecological outcomes, as is the case with adaptive management more generally (Bayley, 1995; Walters, 1997). Uncertainty pervades any form of natural resource management and comes in different forms (Regan, Colyvan \& Burgman, 2002; Milner-Gulland \& Shea, 2017). In this paper we refer to three broad types of uncertainty outlined by Conroy \& Peterson (2013); environmental, statistical and structural uncertainty, explained in Fig. 1 (interested readers can find a more detailed taxonomy of uncertainty in Regan et al. (2002)). The more we lower uncertainty around flow management outcomes, the easier it is to manage both the system and stakeholder expectations, and to achieve environmental outcomes as efficiently as possible (Fig. 1).

In reducing uncertainty, both parameter estimation and hypothesis testing are fundamental goals (Ellison, 1996). When testing hypotheses our focus is primarily on reducing structural uncertainty, while reducing statistical uncertainty may be a higher priority if parameter estimation is our aim (Fig. 1). As we will discuss later (Role 2: Modelling for spatial and temporal projections), quantitative models play a critical role in the adaptive management of riverine flows, and long-term monitoring projects provide the time series required to reduce uncertainty around parameters of models describing the temporal dynamics of systems (Shea, 1998; Clark, Carpenter, Barber et al., 2001; 
Wolkovich, Cook, McLauchlan et al., 2014). Parameter estimation aside, long-term monitoring is often necessary to reduce structural uncertainty about the impact of environmental flows on certain ecological states (e.g. fish population size), which may exhibit delayed (> 5 year) responses to changes in flow regimes (Souchon, Sabaton, Deibel et al., 2008). Within the context of the MDB, the Watering Strategy explicitly recognises that different ecological indicators will likely exhibit responses on very different timescales, and frames management objectives with this in mind (MDBA, 2014a). Short-term monitoring projects ( $<5$ year) may be poorly suited to parameter estimation, but if designed well (see Table 3 ) they too can play a role in reducing structural uncertainty around ecological response to environmental flows.

\section{Role 2: Modelling for spatial and temporal projections}

Quantitative predictive models of the dynamics of river ecosystems facilitate the effective adaptive management of river flows (Anderson, Paul, McCauley et al., 2006; Shenton, Bond, Yen et al., 2012). By increasing our predictive capacity we improve our ability to project flow responses through time, which we hereafter refer to as forecasting, and to scale flow-response dynamics spatially. Following Clark et al. (2001), we define ecological forecasting as the process of predicting the state of riverine ecosystems and their services, with fully specified uncertainties, contingent on explicit scenarios for antecedent ecological state, water availability and climate. By 'state of riverine ecosystems' we mean any physical (e.g. mean water velocity) or biological (e.g. a population) sub-system of the broader ecosystem. Spatial scaling involves using models of flow-response developed at narrow spatial extents and particular locations to predict flow-response dynamics at broader spatial extents and/or different locations (Rastetter, Aber, Peters et al., 2003).

Modelling can facilitate (a) making more effective management decisions; (b) making causal inferences about the effects of environmental water; (c) identifying threats to the efficacy of flow management; (d) scaling flow-response dynamics to broader spatial extents throughout drainage basins.

More informed management decisions

When faced with a decision, flow managers usually have numerous decision options. Which option is likely to yield the best ecological outcomes, given the antecedent ecological state of the system? The success of a decision may depend on the future climatic and flow conditions, so what are the relative advantages and disadvantages of each decision option, given the set of possible climatic futures over the coming years? We cannot answer these questions-hence make wise flow decisions-without strong capacity for ecological forecasting (Polasky, Carpenter, Folke et al., 2011). Within the MDB, the Watering Strategy states that annual water prioritisation involves predicting the likely outcomes of water allocations, given antecedent conditions of the various catchments throughout the MDB 
(MDBA, 2014a). This is a specific flow management problem that would be greatly strengthened by improved capacity for ecological forecasting.

\section{Causal inferences about flow effects}

Drawing robust, causal inferences about the impacts of flows on riverine ecosystems is particularly challenging. If we consider a flow intervention as an experimental treatment, then the treatment cannot be neatly replicated, nor (typically) do we have a control. Thus, the very well established analytical approaches associated with classical experimental design do not often apply to flow interventions (Webb, Stewardson, Chee et al., 2010; Konrad, Olden, Lytle et al., 2011; Olden, Konrad, Melis et al., 2014).

Consider the management objective within the Watering Strategy of delivering water to ensure "no loss or degradation' of key ecological indicators during dry years. This is an interesting analytical problem as the desired treatment effect is 'no change' in the ecological state of a single experimental unit (the river). Achieving this objective requires knowledge of whether failure to deliver the flow would result in a degraded ecological state of that single unit, usually in the absence of a suitable control. Such analytical problems are not unique to river ecology, as analysis of ecological effects in unreplicated, large-scale perturbations is a broader problem in adaptive management (Walters \& Holling, 1990; Stewart-Oaten, Bence \& Osenberg, 1992; Westgate, Likens \& Lindenmayer, 2013). Admirably, Australia's Murray-Darling Basin Authority specifically mentions this analysis problem in their Watering Strategy (MDBA, 2014a) and evaluation framework (MDBA, 2014b). The challenge is also recognised in the Australian Commonwealth's major investment in flow-response monitoring (Gawne, Brooks, Butcher et al., 2013).

One way to determine the effects of flow interventions is through various forms of 'predictive inference' (Gelman \& Hill, 2006; Ch. 9). Although this method of inference is technically challenging, it may help overcome the problem of lacking a classical experimental design (StewartOaten \& Bence, 2001). The approach involves comparing the predicted and/or observed ecological response to an environmental flow with what is predicted to have happened in the absence of the flow (sometimes referred to as the 'counterfactual' or the 'potential outcome'; Gelman \& Hill, 2006; Stewart-Oaten, 2008). As the name suggests, predictive inference requires the capacity to forecast both hydrological and ecological dynamics at various temporal and spatial scales (Webb, de Little, Miller et al., In press). A recent example of this approach is presented by Stewardson \& Skinner (In press), who wished to determine whether a particular flow intervention increased dissolved oxygen concentrations in a lowland stream. They used an oxygen balance model fitted to field measurements to demonstrate that without the flow intervention, environmental hypoxia would likely have ensued, 
with unfavourable consequences for riverine biota (See Webb et al. this issue, for further application of the approach).

\section{Capacity to anticipate emerging threats}

Effective flows policy and management hinges on our capacity to anticipate changes in water availability and other emerging threats (Colloff et al., 2016). For example, a Basin Plan objective is to improve the resilience of the Basin's flora and fauna to climate change and other possible threats (MDBA, 2014a). Meeting this objective requires the ability to anticipate how a changing climate will affect flora and fauna, or how other drivers (e.g. high nutrient concentrations; salinity) will evolve to emerge as threats. Managing water allocations in a non-stationary environment (a form of environmental uncertainty; Fig. 1a), where the flow-response relations of today may change in the future, presents a significant challenge (Bunn \& Arthington, 2002; Wolkovich et al., 2014 discusses the general case).

Consider floodplain vegetation communities: with increased frequency and magnitudes of heat waves and droughts forecast for the mid-latitudes (Sousa, Trigo, Aizpurua et al., 2011; Perkins, Alexander \& Nairn, 2012; Seneviratne, Donat, Mueller et al., 2014), we can expect more frequent physiological stress of floodplain vegetation (Capon, Chambers, Mac Nally et al., 2013; James, Reid \& Capon, 2016). How will this affect the watering requirements of those communities? How well will the inundation rules of today apply in the warming and drying mid-latitudes? Answering such questions requires improved forecasting of both inundation patterns and ecological response to those events.

\section{Spatial scaling of flow outcomes}

Resource management plans often mention the need to 'scale-up' effective management responses observed at particular locations and extents to other locations, where data may be scarce, or to broader spatial extents (Urban, 2005; Gregory, Ohlson \& Arvai, 2006). Within Australia, for example, the Watering Strategy clearly states the need for a 'basin-wide' approach to water planning and management (MDBA, 2014a). This basin-wide planning approach has extended to evaluation, such that the Commonwealth's major flow monitoring program has the objective of evaluating outcomes to flow interventions within unmonitored catchments (Gawne et al., 2013). Here again the solution is predictive inference; using quantitative models to predict what the likely outcomes of a management intervention would have been in an unmonitored location (Ferrier, 2011). Accuracy of these predictions will vary substantially, depending on statistical uncertainty around model parameters, how dependent parameter values are on environmental context, information on the ecological state of the unmonitored location, and hydrological/hydraulic information, including data on the background and managed components of the hydrograph. A critical step towards improving accuracy of spatial scaling is assessing the transferability of model predictions (Wenger \& Olden, 2012). As is the case for all 
ecological forecasting, the predictions should not be seen as definitive statements of what has happened as a result of the flow, but statements about the range of likely outcomes, given fullyspecified assumptions and uncertainties (Clark et al., 2001).

\section{Role 3: Fundamental research}

We here define fundamental research as any empirical or theoretical research aimed at increasing our understanding of the basic relationships between riverine flows and ecological pattern and process. Given this definition, monitoring can be considered a subset of fundamental research, but a key point of difference between monitoring and fundamental research projects is that the latter are not necessarily tied to a managed flow intervention. For example, empirical fundamental research may range from studying the relationships between natural flow variability and ecological responses (e.g. Mims \& Olden, 2012), through to controlled laboratory experiments aimed at elucidating cause-effect mechanisms in riverine food webs (e.g. Baldwin, Whitworth \& Hockley, 2014). Fundamental theoretical work can be similarly broad and may range from conceptual syntheses of flow ecology (e.g. Junk, Bayley \& Sparks, 1989; Poff, Allan, Bain et al., 1997), through to exploring dynamic ecological responses to flows with mathematical models (e.g. Power, Sun, Parker et al., 1995). Of course, not all sources of structural uncertainty have equal influence on the total level of uncertainty concerning the outcomes of decisions. It follows that not all fundamental research questions concerning flow ecology are equally important to managers (see Barriers to fundamental research). Nevertheless, as argued by McDonald-Madden et al. (2010; 2011) we contend that, in many cases, reduction of structural uncertainty around the outcomes of flow decisions may be more effectively and efficiently reduced with fundamental research than with monitoring.

Fundamental research will lead to at least two desirable outcomes for flow managers, which we discuss briefly below.

\section{Improved flow outcomes through synergistic river management}

Flows have become such a prominent issue in river management that we often fall into the trap of thinking that flow manipulation is the single and best way to meet our ecological objectives.

However, flows interact with many other environmental variables to shape ecological outcomes. Fundamental research to elucidate those interactions may lead to synergistic river management solutions that provide greater ecological returns per unit of environmental water invested.

As an example, consider the possible role of large woody debris in mediating the response of nutrient cycles to flows. Fundamental research has shown that overbank flooding plays an important role in mobilising and transporting dissolved nutrients between channel and floodplain habitats (Junk et al., 1989; Baldwin, Rees, Wilson et al., 2013; Cook, Gawne, Petrie et al., 2015). Whether or not these 
dissolved nutrients are incorporated into the riverine food web may be determined by the densities of certain microbes in a river reach, which may in turn be affected by availability of hard substrates for microbial colonisation. Simple laboratory experiments have confirmed that the surface area of hard microbial substrates exhibits a strong, positive relationship with dissolved nutrient uptake (Baldwin et $a l ., 2014)$. This fundamental research efficiently shows that while flows may be crucial for mobilising and transporting nutrients, habitat structure plays a pivotal role in converting these biogeochemical outcomes into outcomes with more tangible value to stakeholders (e.g. more fish). The application is that joint management of woody debris and flows may yield synergistic benefits.

\section{Improved understanding about how well current policy fulfils management objectives}

Consider the following scenario, germane to Australia's Basin Plan: Water policy dictates (a) the amounts of water, and (b) the domain of hydrological variability available to managers for meeting ecological objectives. Due to water diversions and delivery constraints (e.g. floodplain infrastructure), the domain of hydrological variation for managed flows is a subset of the broader domain of natural flow variability (Spring, Croft, Bond et al., submitted). The legislation that sets the amounts and constraints for delivery may be up for periodic review — as is the case for the SDL (MDBA, 2014a) and any such review needs to be informed by an improved scientific understanding of the system. How do we best improve our scientific understanding of ecological response to flow variability beyond the constraints of the current policy framework?

One may argue that the best way to improve our understanding in this situation is through monitoring. However, this would be a non sequitur, and would result in us primarily drawing inferences about the effects of the reduced domain of variability set by the current water policy. How can we provide scientific recommendations towards revising the current domain of variability if our ecological understanding is completely circumscribed by that domain? Within the Murray-Darling Basin, for example, meeting certain Basin Plan objectives may depend on the extent to which we can reconnect floodplain and channel habitats, but current legislation restricts most flows to the main channel (Bond, Costelloe, King et al., 2014; Stoffels, Clarke, Rehwinkel et al., 2014). This, coupled with the fact we generally have a very poor understanding of the significance of river-floodplain connectivity to biota, implies that monitoring managed flows may be an ineffective way to improve our understanding of how delivery constraints affect our ability to meet management objectives.

In such situations, fundamental research is likely the most efficient way to reduce structural uncertainty (McDonald-Madden et al., 2010). Working with the above example, we need more fundamental research into the ecological consequences of river-floodplain connectivity scenarios. This research could take place in systems with minimal regulation of river-floodplain connectivity, or take novel experimental approaches towards better understanding how environmental conditions in 
floodplain and channel habitats (e.g. temperature) affect ecological processes. Inferences derived from such research could be scaled-up using models to forecast how relaxing river-floodplain connectivity constraints affect ecological dynamics at broader spatial scales.

\section{Role 4: Decision science}

An ultimate test of the utility of freshwater science to stakeholders is how well it supports effective and efficient flow-allocation decisions. We have already discussed the importance of predictive capacity in supporting decisions, but there are several other ways that scientists can strengthen the decision-making processes of flow management. Indeed, over the last two decades we have seen the emergence of numerous scientific applications aimed entirely at how we can use information to make smarter decisions when managing our natural resources (Burgman, 2005). For convenience, we refer collectively to these scientific applications as 'ecological decision science' ('decision science' hereafter).

Decision science operates at the interface between ecological science and natural resource management. It is an interdisciplinary field that develops scientific tools to integrate multiple forms of data (e.g. ecological; economic) to make transparent and replicable decisions about how resources should be allocated to effectively and efficiently meet management objectives. Within the context of flow management, applications within decision science offer at least two beneficial outcomes: (a) more defensible environmental flow decisions; (b) more efficient use of resources to support adaptive management of flows.

\section{Defensible flow decisions}

The intersection of two problems creates the need for robust and transparent decision-making processes: The first problem we face is the fact that decisions will be scrutinised by economic, consumer and political stakeholders (Table 1). The level of scrutiny aimed at water managers will only increase as competition among stakeholders for freshwater increases (Vorosmarty et al., 2000). The second problem is that there is currently very high uncertainty about the outcomes from any particular flow allocation decision.

This combination of having to make decisions in a high-stakes game, yet being uncertain about the outcomes of our decisions, necessitates the employment of decision-making processes recommended by decision science (e.g. Gregory, Failing, Harstone et al., 2012). Russo \& Shoemaker (2001) summarise the need for a defensible decision-making process as a two-way table; note the distinction between decision processes and outcomes (Table 2). 
The MDB Watering Strategy acknowledges the need for 'robust and transparent decisions' in their annual water planning, but without mentioning how they would achieve this (MDBA, 2014a).

Decision science offers frameworks for making objective and transparent decisions, despite what may appear to be unruly uncertainty. Towards that end, Conroy \& Peterson (2013) broadly suggest three steps:

1. Set explicit, quantifiable management objectives in light of ecological knowledge, economic data and stakeholder values. This step will, of course, involve considerable engagement with all key stakeholder groups.

2. Model the relationships between explicit decision alternatives and objectives. Using best available ecological and economic information, quantitative models are developed that describe the relations between the suite of alternative decisions available and management objectives. The models may explicitly incorporate operating and financial constraints associated with alternative decisions, as well as the trade-offs among decision options.

3. Modelling the outcomes, trade-offs and uncertainties associated with taking alternative decisions. Quantitative models are used to predict the likely outcomes, uncertainties and trade-offs associated with alternative decisions. This quantitative assessment of decision performance against clear objectives, then serves as critical input to finalising decisions, which should again involve participation of key stakeholders (also see Martin, Powell, Webb et al., 2017).

\section{More efficient use of resources}

'Efficiency' is a key word in the management of riverine flows. Environmental water is a scarce and expensive commodity, so must be used to meet management objectives in the most efficient way (Bunn \& Arthington, 2002). Likewise, funding to fulfil the four roles discussed herein is also a scarce resource, and so must be distributed to maximise returns per unit investment (McDonald-Madden et al., 2010). In both these cases we seek an optimal resource allocation. Decision science offers solutions to such optimisation problems, and we discuss two such applications here.

Federal water managers within Australia are responsible for prioritising water allocations to numerous floodplain reserves throughout the Murray-Darling Basin (MDBA, 2014a) (Questions 3 and 6 in Fig. 2). During wet years this may not be a particularly great challenge. By contrast, during drought the magnitude of the challenge increases. During drought should we deliver a small volume of water to all reserves, or deliver a larger amount of water to those reserves that need it most over the coming year? How do we decide which reserves 'need it most'? Making such decisions will be very difficult for many reasons, not least of which is that, during dry years, passionate regional stakeholder groups with potentially conflicting objectives will exert their strongest influence on watering decisions. However, even in the absence of stakeholder pressure, deciding which reserves to water will be non-trivial from 
a purely technical standpoint. Such decisions will undoubtedly be characterised by multiple competing objectives (insufficient water to fulfil all objectives at large scales), and possibly conflicting objectives (fulfilment of one objective comes at the expense of another, irrespective of water avilability; Conroy \& Peterson 2013). Further, the costs of decision options may go well beyond volumes of water and may include, for example: a year without breeding for certain wetlanddependent waterfowl; localised extinction of a floodplain fish species; mortality of plant seeds in the soil seedbank. Understanding the longer-term consequences of these short-term impacts once again requires predictive models able to project forward over multi-year time horizons (Role 2).

Procedures in decision science help optimise resource allocation when faced with multiple interacting objectives, like those that characterise the water allocation problem described above. The goal is to find a pattern of water allocation across reserves that maximises ecological 'returns' within a budget defined by ecological and/or financial costs (or, alternatively, achieves a target ecological return for minimum cost) (Cabeza \& Moilanen, 2001). In the simplest characterisation, ecological returns might be the number of floodplain species among reserves likely to benefit from water, and ecological costs might be the number of species among reserves likely to suffer reduced abundance and/or range as a consequence of missing out. Taking this static view of the problem, the optimisation procedure utilised might resemble one of the well-known reserve-design algorithms employed by decision scientists, where the objective is to either find the spatial pattern of conservation reserves that protects the most species for a fixed cost, or to protect all species for the lowest cost (Possingham, Ball \& Andelman, 2000; Cabeza \& Moilanen, 2001; Linke, Turak \& Nel, 2011).

However, our decision problem is more complicated. The floodplain species we wish to sustain have varying degrees of resistance and resilience to drought (Bond, Lake \& Arthington, 2008; Capon et al., 2013; Stoffels, 2015), and each floodplain reserve may have experienced a unique watering history over preceding years. That is, the relative rewards and costs of watering decisions are dynamic and will vary across years. For example, the costs of not watering certain reserves will depend on factors additional to just volumes of water and species that miss out in a single year, such as: (A) The recent inundation history of those reserves; what is their current ecological and hydrological state? (B) The relative resistance and resilience of species to future inundation scenarios; how much more drying can the community endure? (C) The forecast climatic/hydrological conditions among reserves in future years; what are the future levels of drying risk among reserves? Optimisation models for this particular problem are now being developed (Horne, Szemis, Webb et al., 2018). Nevertheless, decision scientists have begun developing dynamic resource allocation models, identifying optimal patterns of water allocation to wetlands given past hydrological variability and future hydrological scenarios (Yang, 2011; Nicol, Griffith, Austin et al., 2014). We anticipate further developments in 
this field of decision science, towards facilitation of complex, multi-objective decision problems in flows management in the near future.

A second application of tools developed in decision science is to the problem of how to most efficiently invest in research to reduce uncertainty. Assume that we have numerous hypotheses about how uncertainty reduces our ability to achieve management objectives, but that monitoring and management require us to expend limited resources so that we can only reduce one of the many uncertainties; which uncertainty should we choose to reduce? Value of information analysis quantifies the value of reducing uncertainty in a decision-making process (Milner-Gulland \& Shea, 2017). The expected value of perfect information (EVPI) is the difference between the expected management outcomes when a decision is made using existing information and when the decision is made after collecting new information (Yokota \& Thompson, 2004; Canessa, Guillera-Arroita, Lahoz-Monfort et al., 2015). In plain language, EVPI asks: 'how much better would my management outcomes be if I could remove the uncertainty?' Value of information analysis can quantify the expected gains from a range of hypotheses relatively rapidly using existing information, enabling decision makers to invest scarce resources into promising hypotheses with more confidence about the expected returns. This is particularly useful when considering investment in resource-intensive, long-term adaptive management programs, where it is important to have confidence that the uncertainties targeted will make the largest difference to management outcomes.

\section{Barriers to implementation and some solutions}

Having presented the 'four roles' that we believe scientists must fulfil to support management of riverine flows, we now discuss some major barriers to effective and efficient fulfilment of those roles.

\section{One overarching barrier-the need for basin-scale science investment strategies}

Before briefly discussing barriers specific to each role, we first argue that one of the greatest overarching impediments to successful fulfilment of the scientific roles is the absence of scienceinvestment strategies at the scale of entire drainage basins. We contend that, in the absence of an investment strategy, scientific support of water management risks becoming inefficient. There are several reasons for this, and we touch on just two below.

First, absence of a basin-scale strategy results in ad hoc science investment patterns that do not cover the most commonly-faced and/or most consequential decisions that water managers must make. Fig. 2 presents a subset of the decisions facing managers in Australia's MDB, across the suite of spatial and temporal scales acknowledged in the Watering Strategy (MDBA, 2014a). The decisions specifically concern the management of hydrological connectivity between rivers and floodplains. Funding for science is scarce, so developing a science plan to answer the questions in Fig. 2 requires a basin-scale, 
strategy. This basin-scale strategy would collaboratively prioritise science investments in a holistic fashion, in light of the management decisions that need to be made at multiple spatial and temporal scales. It is currently commonplace, however, to observe science investment dominated by local and regional spatial scales, and short temporal scales (i.e. monthly-annual). These two approaches may be considered 'top-down' and 'bottom-up' respectively, and each may have its strengths. However, combined approaches that mix the high level efficiencies and big-picture problem framing of topdown approaches with the ability of 'bottom-up' approaches to capture tangible real-world problems are proving successful (Coleman, Bathgate, Bond et al., 2016).

Second, absence of an investment strategy results in scientists and managers achieving a poor shared understanding of (a) why all four scientific roles are required to support flow management; (b) how they can complement each other to meet scientific objectives around reducing uncertainty, reporting, and supporting decisions. Arguably, many water management agencies now view the primary role of scientists as designing and executing monitoring projects. This is reflected in the distribution of funding within Australia, where almost all funding for science to support flows management gets channelled into monitoring.

We suggest developing a science investment strategy according to the following three principles: First, the strategy must be developed at the basin-scale. As previously discussed, a basin-scale strategy is required to avoid ad hoc investment and have science adequately supporting flows management at the relevant spatial and temporal scales. The strategy should consider the specific management decisions that need to be made at the various spatial and temporal scales.

Second, the strategy must be developed by a consortium of stakeholders across the relevant jurisdictional scales to ensure that science investments remain aligned with the specific needs and constraints of water managers (Sutherland, Bellingan, Bellingham et al., 2012; Coleman et al., 2016).

Third, the strategy must recognise the need to build and maintain capacity within the four scientific roles presented earlier. The scientific skills required to successfully fulfil the four roles presented herein are in short supply. This is particularly true for modelling and decision science (Gregory et al., 2006). We must not assume that the technical skills required to fulfil all roles can be accessed and then stored in an ad hoc fashion, so the strategy should be developed to build and nurture technical capacity for all four roles.

\section{Barriers to monitoring and evaluation}

Our experiences lead us to suggest that poor practice in design and implementation is the major barrier to effective flow monitoring and evaluation projects (Souchon et al., 2008). Poor practice 
extends well beyond riverine programs, with ecological monitoring programs often delivering low returns per unit investment (Nichols \& Williams, 2006; Lovett, Burns, Driscoll et al., 2007;

Lindenmayer \& Likens, 2010; McDonald-Madden et al., 2010). Both long- and short-term monitoring projects have a place in reducing uncertainty. However, as described earlier (Role 1: Monitoring and evaluation), they have different uses. Monitoring projects should have clearly articulated goals that state the assumed conceptual model and whether they aim to resolve structural uncertainty (i.e. short term monitoring may be appropriate) or to improve parameter estimates (i.e. long term monitoring may be appropriate).

We offer six guidelines for effective monitoring and evaluation in Table 3. Examination of those guidelines reveals effective and efficient monitoring and evaluation of flows cannot occur without strong scientific involvement-from design, through to implementation, analysis and communication of outcomes-as well as strong partnerships between stakeholders.

In addition to barriers to efficacy, a major barrier to efficiency is poor coordination of multiple monitoring projects across jurisdictional (e.g. international, federal, state, and regional agencies), spatial and temporal scales. Within Australia we see a proliferation of flow monitoring projects conducted over various spatial and temporal scales that, on their own, yield little in terms of scientifically-defensible reporting of flow outcomes and reduction of uncertainty. While they may add little value on their own, together they comprise enormous investment and, if strategically and scientifically coordinated, could yield far higher return on investment. If further monitoring projects are deemed necessary, they absolutely must be designed with a clear vision for how they complement existing monitoring and research activities. How will the data obtained with one monitoring project be combined with that of another, such that genuine synergies arise in robust reporting and reduced uncertainty? Answering this question would be a key challenge to tackle as part of the basin-scale science investment strategy mentioned above. Lindenmayer and Likens (2010) suggested that integration of knowledge from different monitoring projects is one of the greatest challenges facing scientific monitoring and evaluation.

\section{Barriers to modelling}

As has long been recognised, arguably the greatest impediment to the parameterisation of models for effective eeological forecasting is the absence of appropriate data (Walters, 1997; Shea, 1998; Wolkovich et al., 2014; Honrado, Pereira \& Guisan, 2016). Quality, long-term time series are essential for estimating parameters of models of temporal dynamics. The required frequency and duration of measurements will depend on the ecological indicators being modelled, but for certain indicators (e.g. long-lived fish populations) annual censuses over 20 years or more may be required to reduce statistical uncertainty to desirable levels (Walters, 1997). Long-term monitoring programs 
provide the data required to improve our capacity to forecast outcomes and anticipate change. Importantly, the presence of uncertainty should not stop model parameterisation and use in adaptive management while data is collected (Clark et al., 2001).

\section{Barriers to fundamental research}

Funding is often allocated to fundamental research by water managers following a crisis, with the research aimed at reducing uncertainty around what caused the crisis. Specific examples include floodplain acidification (Baldwin \& Fraser, 2009) and hypoxic blackwater flows (Whitworth, Baldwin $\&$ Kerr, 2012) following extreme water diversion. A smarter approach to investment would be to anticipate possible threats, identify uncertainties around how those threats operate and/or can be managed, then prioritise fundamental research accordingly. Methods exist for the collaborative, systematic identification and prioritisation of threats (e.g. Sutherland \& Woodroof, 2009; Sutherland, Fleishman, Mascia et al., 2011) and, in turn, identification and prioritisation of sources of uncertainty underlying how best to manage those threats (Role 4: Decision science; More efficient use of resources). Arguably, however, the dominant barrier to fundamental research is not methodological, but lack of appreciation by investors of the value of fundamental research-as opposed to monitoring- to the management of riverine flows. It follows that any collaborative prioritisation of fundamental research must include several stakeholders, particularly those with the capacity to invest in such research. Collaborative identification of fundamental research priorities should be part of the basin-scale science investment strategy, such that we obtain knowledge to avoid crises, rather than achieving a post-hoc understanding of how they occurred.

\section{Barriers to decision science}

Obtaining the efficacy and efficiency benefits that come with employing decision science requires cultural change in both science and management. Scientists need to shift their focus towards building stronger partnerships with managers such that the decision problems managers face are better understood. This may take significant time away from other more traditional performance indicators that scientists aim for, and so institutional change in reward systems may also be required. All riverine management decisions come with costs; some may yield rewards. The costs of decision options must be considered systematically during decision-making processes, if we are to improve the efficacy and efficiency of flows management.

Decision science is most effective when objectives are clearly expressed, quantitative and time-bound. Perhaps surprisingly, few agencies achieve this in their management plans. Part of the controversy (and arguably the success) of the Basin Plan is that it sets specific flow regimes and outlines relatively clear objectives, making it enforceable and allowing decision-makers to track success. However in many other ecological systems, there may be an aversion to committing to specific targets in case they 
are not achieved, despite the fact that all ecological systems are subject to many sources of uncertainty. This fear of 'failure' can undermine the ability of decision science to report on success and, more importantly, can obfuscate learnings because of imprecise goals. Management agencies that set clear priorities and embrace a culture of learning will stand to gain the most from decision science.

Different management agencies, at different jurisdictional scales, often have their own conventions when it comes to how science is brought to bear on flow decisions. Burgman (2005) notes that the approach to making decisions in the face of uncertainty should be determined by data, questions and analytical needs, not by professional convention. Accordingly, if we are to align decision-making processes with best-practice, then greater consistency of process across jurisdictions must be achieved, and those consistent processes have been provided by decision scientists (Gregory et al., 2012; Conroy \& Petersen, 2013).

\section{Conclusion}

The last two decades have been a transformational period in riverine flow ecology and management (Arthington, 2012). In writing this paper we have taken a step back from our usual scientific tasks and asked: how does science need to operate if it is to best support riverine flow management? We have mapped out the four major roles that must be fulfilled, and identified some major impediments—and solutions - to progress. The problems we identify, and solutions we offer, transcend riverine flows management and so our arguments are likely applicable to all ecosystems. In mapping out these four roles we have been optimistic in our outlook, but not naively so; we appreciate that cultural norms in research and management often appear inert, and evolve slowly. Given that the competition for riverine flows is increasing (Vorosmarty et al., 2000), the next two decades will place even greater demands on the skills of scientists and managers, and the strength of their collaborations. Scientists and managers must quickly strengthen partnerships at multiple scales to develop wise science investment strategies, so that we can effectively and efficiently maintain our socio-political license to operate, reduce uncertainty, and transform knowledge into smart flow decisions.

\section{Acknowledgements}

We thank the Murray-Darling Basin Officials Committee and Jane Doolan for challenging us to reconsider how ecologists can best support the decision problems of flows management. This work was funded by the Murray-Darling Basin Joint Governments. All opinions/inferences are those of the authors, not of the MDBA, nor the Joint Governments. The authors have no conflict of interest to declare. We are grateful to Angus Webb, Jonathan Kennan and Eric Stein for inviting us to contribute to this special issue of Freshwater Biology. We thank Carmel Pollino, Angus Webb and two anonymous referees for their helpful reviews of earlier drafts. 


\section{References}

Acreman, M., Arthington, A.H., Colloff, M.J., Couch, C., Crossman, N.D., Dyer, F., Overton, I., Pollino, C.A., Stewardson, M.J. \& Young, W. (2014) Environmental flows for natural, hybrid, and novel riverine ecosystems in a changing world. Frontiers in Ecology and the Environment, 12, 466-473.

Anderson, K.E., Paul, A.J., Mccauley, E., Jackson, L.J., Post, J.R. \& Nisbet, R.M. (2006) Instream flow needs in streams and rivers: the importance of understanding ecological dynamics. Frontiers in Ecology and the Environment, 4, 309-318.

Arthington, A.H. (2012) Environmental Flows: Saving Rivers in the Third Millenium, University of California Press, California.

Arthington, A.H., Bunn, S.E., Poff, N.L. \& Naiman, R.J. (2006) The challenge of providing environmental flow rules to sustain river ecosystems. Ecological Applications, 16, 1311-1318.

Arthington, A.H., Naiman, R.J., Mcclain, M.E. \& Nilsson, C. (2010) Preserving the biodiversity and ecological services of rivers: new challenges and research opportunities. Freshwater Biology, $55,1-16$.

Baldwin, D.S. \& Fraser, M. (2009) Rehabilitation options for inland waterways impacted by sulfidic sediments - A synthesis. Journal of Environmental Management, 91, 311-319.

Baldwin, D.S., Rees, G.N., Wilson, J.S., Colloff, M.J., Whitworth, K.L., Pitman, T.L. \& Wallace, T.A. (2013) Provisioning of bioavailable carbon between the wet and dry phases in a semi-arid floodplain. Oecologia, 172, 539-550.

Baldwin, D.S., Whitworth, K.L. \& Hockley, C.L. (2014) Uptake of dissolved organic carbon by biofilms provides insights into the potential impact of loss of large woody debris on the functioning of lowland rivers. Freshwater Biology, 59, 692-702.

Bayley, P.B. (1995) Understanding large river-floodplain ecosystems. Bioscience, 45, 153-158.

Bernhardt, E.S., Palmer, M.A., Allan, J.D., Alexander, G., Barnas, K., Brooks, S., Carr, J., Clayton, S., Dahm, C., Follstad-Shah, J., Galat, D., Gloss, S., Goodwin, P., Hart, D., Hassett, B., Jenkinson, R., Katz, S., Kondolf, G.M., Lake, P.S., Lave, R., Meyer, J.L., O'donnell, T.K., Pagano, L., Powell, B. \& Sudduth, E. (2005) Ecology - Synthesizing US river restoration efforts. Science, 308, 636637

Bond, N., Costelloe, J., King, A., Warfe, D., Reich, P. \& Balcombe, S. (2014) Ecological risks and opportunities from engineered artificial flooding as a means of achieving environmental flow objectives. Frontiers in Ecology and the Environment, 12, 386-394.

Bond, N.R., Lake, P.S. \& Arthington, A.H. (2008) The impacts of drought on freshwater ecosystems: an Australian perspective. Hydrobiologia, 600, 3-16.

This article is protected by copyright. All rights reserved 
Bunn, S.E. \& Arthington, A.H. (2002) Basic principles and ecological consequences of altered flow regimes for aquatic biodiversity. Environmental Management, 30, 492-507.

Burgman, M.A. (2005) Risks and Decisions for Conservation and Environmental Management, Cambridge University Press, Cambridge, UK.

Cabeza, M. \& Moilanen, A. (2001) Design of reserve networks and the persistence of biodiversity. Trends in Ecology \& Evolution, 16, 242-248.

Canessa, S., Guillera-Arroita, G., Lahoz-Monfort, J.J., Southwell, D.M., Armstrong, D.P., Chades, I., Lacy, R.C. \& Converse, S.J. (2015) When do we need more data? A primer on calculating the value of information for applied ecologists. Methods in Ecology and Evolution, 6, 1219-1228.

Capon, S.J., Chambers, L.E., Mac Nally, R., Naiman, R.J., Davies, P., Marshall, N., Pittock, J., Reid, M., Capon, T., Douglas, M., Catford, J., Baldwin, D.S., Stewardson, M., Roberts, J., Parsons, M. \& Williams, S.E. (2013) Riparian Ecosystems in the 21st Century: Hotspots for Climate Change Adaptation? Ecosystems, 16, 359-381.

Clark, J.S., Carpenter, S.R., Barber, M., Collins, S., Dobson, A., Foley, J.A., Lodge, D.M., Pascual, M., Pielke, R., Pizer, W., Pringle, C., Reid, W.V., Rose, K.A., Sala, O., Schlesinger, W.H., Wall, D.H. \& Wear, D. (2001) Ecological forecasts: An emerging imperative. Science, 293, 657-660.

Coleman, R.A., Bathgate, R., Bond, N., Bos, D., Fletcher, T.D., Lovell, B., Morison, P. \& Walsh, C.J. (2016) Improving waterway management outcomes through collaborative research: insights from the Melbourne Waterway Research-Practice Partnership In: Proceedings of the 8th Australian Stream Management Conference. (Ed^^Eds G.J. Vietz \& A.J. Flatley \& I.D. Rutherfurd), pp. 301-309. River Basin Management Society.

Colloff, M.J., Lavorel, S., Wise, R.M., Dunlop, M., Overton, I.C. \& Williams, K.J. (2016) Adaptation services of floodplains and wetlands under transformational climate change. Ecological Applications, 26, 1003-1017.

Colloff, M.J., Ward, K.A. \& Roberts, J. (2014) Ecology and conservation of grassy wetlands dominated by spiny mud grass Pseudoraphis spinescens in the southern Murray-Darling Basin, Australia. Aquatic Conservation-Marine and Freshwater Ecosystems, 24, 238-255.

Conroy, M.J. \& Petersen, J.T. (2013) Decision Making in Natural Resource Management: A Sructured, Adaptive Approach, John Wiley and Sons, Ltd, Chichester, UK.

Cook, R.A., Gawne, B., Petrie, R., Baldwin, D.S., Rees, G.N., Nielsen, D.L. \& Ning, N.S.P. (2015) River metabolism and carbon dynamics in response to flooding in a lowland river. Marine and Freshwater Research, 66, 919-927.

Ellison, A.M. (1996) An introduction to Bayesian inference for ecological research and environmental decision-making. Ecological Applications, 6, 1036-1046.

This article is protected by copyright. All rights reserved 
Ferrier, S. (2011) Extracting More Value from Biodiversity Change Observations through Integrated Modeling. Bioscience, 61, 96-97.

Gawne, B., Brooks, S., Butcher, R., Cottingham, P., Everingham, P., Hale, J., Nielson, D., Stewardson, M. \& Stoffels, R. (2013) Long-term Intervention Monitoring Logic and Rationale Document prepared for the Commonwealth Environmental Water Office. p. 119, The Murray-Darling Freshwater Research Centre, MDFRC Publication 01/2013.

Gelman, A. \& Hill, J. (2006) Data Analysis Using Regression and Multilevel/Hierarchical Models, Cambridge University Press.

Gregory, R., Failing, L., Harstone, M., Long, G., Mcdaniels, T. \& Ohlson, D. (2012) Structured Decision Making: A Practical Guide to Environemntal Management Choices, John Wiley \& Sons Ltd, West Sussex, UK.

Gregory, R., Ohlson, D. \& Arvai, J. (2006) Deconstructing adaptive management: Criteria for applications to environmental management. Ecological Applications, 16, 2411-2425.

Hart, B.T. (2016) The Australian Murray-Darling Basin Plan: challenges in its implementation (part 1). International Journal of Water Resources Development, 32, 819-834.

Hobbs, R.J., Higgs, E. \& Harris, J.A. (2009) Novel ecosystems: implications for conservation and restoration. Trends in Ecology \& Evolution, 24, 599-605.

Honrado, J.P., Pereira, H.M. \& Guisan, A. (2016) Fostering integration between biodiversity monitoring and modelling. Journal of Applied Ecology, 53, 1299-1304.

Horne, A., Szemis, J.M., Webb, J.A., Kaur, S., Stewardson, M.J., Bond, N.R. \& Nathan, R. (2018) The challenge of translating ecology to inform environmental water management decisions: the requirements of planning and implementation cycles. Environmental Management.

James, C., Reid, M. \& Capon, S. (2016) Climate change and the future of Australian riverine vegetation. In: Vegetation of Australian Riverine Landscapes: Biology, Ecology and Management. (Ed^Eds S. Capon \& C. James \& M. Reid), pp. 387-405. CSIRO Publishing, Australia.

Junk, W.J., Bayley, P.B. \& Sparks, R.E. (1989) The flood-pulse concept in river-floodplain systems. In: Proceedings of the International Large River Symposium. (Ed^Eds D.P. Dodge), pp. 110-127. Canadian Special Publications in Fisheries and Aquatic Sciences.

Kingsford, R.T. (2000) Ecological impacts of dams, water diversions and river management on floodplain wetlands in Australia. Austral Ecology, 25, 109-127.

Konrad, C.P., Olden, J.D., Lytle, D.A., Melis, T.S., Schmidt, J.C., Bray, E.N., Freeman, M.C., Gido, K.B., Hemphill, N.P., Kennard, M.J., Mcmullen, L.E., Mims, M.C., Pyron, M., Robinson, C.T. \& 
Williams, J.G. (2011) Large-scale Flow Experiments for Managing River Systems. Bioscience, 61, 948-959.

Lake, P.S. \& Bond, N.R. (2007) Australian futures: Freshwater ecosystems and human water usage. Futures, 39, 288-305.

Lindenmayer, D.B. \& Likens, G.E. (2009) Adaptive monitoring: a new paradigm for long-term research and monitoring. Trends in Ecology \& Evolution, 24, 482-486.

Lindenmayer, D.B. \& Likens, G.E. (2010) The science and application of ecological monitoring. Biological Conservation, 143, 1317-1328.

Linke, S., Turak, E. \& Nel, J. (2011) Freshwater conservation planning: the case for systematic approaches. Freshwater Biology, 56, 6-20.

Lovett, G.M., Burns, D.A., Driscoll, C.T., Jenkins, J.C., Mitchell, M.J., Rustad, L., Shanley, J.B., Likens, G.E. \& Haeuber, R. (2007) Who needs environmental monitoring? Frontiers in Ecology and the Environment, 5, 253-260.

Lubchenco, J. (1998) Entering the century of the environment: A new social contract for science. Science, 279, 491-497.

Maheshwari, B.L., Walker, K.F. \& Mcmahon, T.A. (1995) Effects of regulation on the flow regime of the River Murray, Australia. Regulated Rivers-Research \& Management, 10, 15-38.

Martin, D.M., Powell, S.J., Webb, J.A., Nichols, S.J. \& Poff, N.L. (2017) An Objective Method to Prioritize Socio-Environmental Water Management Tradeoffs Using Multi-Criteria Decision Analysis. River Research and Applications, 33, 586-596.

Mcdonald-Madden, E., Baxter, P.W.J., Fuller, R.A., Martin, T.G., Game, E.T., Montambault, J. \& Possingham, H.P. (2010) Monitoring does not always count. Trends in Ecology \& Evolution, 25, 547-550.

Mcdonald-Madden, E., Baxter, P.W.J., Fuller, R.A., Martin, T.G., Game, E.T., Montambault, J. \& Possingham, H.P. (2011) Should we implement monitoring or research for conservation? Trends in Ecology \& Evolution, 26, 108-109.

Mcmahon, T.A. \& Finlayson, B.L. (2003) Droughts and anti-droughts: the low flow hydrology of Australian rivers. Freshwater Biology, 48, 1147-1160.

Mdba (2014a) Basin-wide environmental watering strategy. Licensed from the Murray-Darling Basin Authority, under a Creative Commons Attribution 3.0 Australia Licence.

Mdba (2014b) Murray-Darling Basin water reforms: Framework for evaluating progress. Licensed from the Murray-Darling Basin Authority, under a Creative Commons Attribution 3.0 Australia Licence.

This article is protected by copyright. All rights reserved 
Milner-Gulland, E.J. \& Shea, K. (2017) Embracing uncertainty in applied ecology. Journal of Applied Ecology, n/a-n/a.

Mims, M.C. \& Olden, J.D. (2012) Life history theory predicts fish assemblage response to hydrologic regimes. Ecology, 93, 35-45.

Naiman, R.J., Bunn, S.E., Nilsson, C., Petts, G.E., Pinay, G. \& Thompson, L.C. (2002) Legitimizing fluvial ecosystems as users of water: An overview. Environmental Management, 30, 455-467.

Nichols, J.D. \& Williams, B.K. (2006) Monitoring for conservation. Trends in Ecology \& Evolution, 21, 668-673.

Nicol, S. \& Chades, I. (In prep) Prioritising the value of monitoring for multiple criteria: a case study using Moira Grass in the Murray River at Barmah-Millewa forest.

Nicol, S., Griffith, B., Austin, J. \& Hunter, C.M. (2014) Optimal water depth management on river-fed National Wildlife Refuges in a changing climate. Climatic Change, 124, 271-284.

Nilsson, C., Reidy, C.A., Dynesius, M. \& Revenga, C. (2005) Fragmentation and flow regulation of the world's large river systems. Science, 308, 405-408.

Olden, J.D., Konrad, C.P., Melis, T.S., Kennard, M.J., Freeman, M.C., Mims, M.C., Bray, E.N., Gido, K.B., Hemphill, N.P., Lytle, D.A., Mcmullen, L.E., Pyron, M., Robinson, C.T., Schmidt, J.C. \& Williams, J.G. (2014) Are large-scale flow experiments informing the science and management of freshwater ecosystems? Frontiers in Ecology and the Environment, 12, 176185.

Perkins, S.E., Alexander, L.V. \& Nairn, J.R. (2012) Increasing frequency, intensity and duration of observed global heatwaves and warm spells. Geophysical Research Letters, 39, 5.

Poff, N.L., Allan, J.D., Bain, M.B., Karr, J.R., Prestegaard, K.L., Richter, B.D., Sparks, R.E. \& Stromberg, J.C. (1997) The natural flow regime. Bioscience, 47, 769-784.

Poff, N.L., Allan, J.D., Palmer, M.A., Hart, D.D., Richter, B.D., Arthington, A.H., Rogers, K.H., Meyers, J.L. \& Stanford, J.A. (2003) River flows and water wars: emerging science for environmental decision making. Frontiers in Ecology and the Environment, 1, 298-306.

Poff, N.L., Richter, B.D., Arthington, A.H., Bunn, S.E., Naiman, R.J., Kendy, E., Acreman, M., Apse, C., Bledsoe, B.P., Freeman, M.C., Henriksen, J., Jacobson, R.B., Kennen, J.G., Merritt, D.M., O'keeffe, J.H., Olden, J.D., Rogers, K., Tharme, R.E. \& Warner, A. (2010) The ecological limits of hydrologic alteration (ELOHA): a new framework for developing regional environmental flow standards. Freshwater Biology, 55, 147-170.

Polasky, S., Carpenter, S.R., Folke, C. \& Keeler, B. (2011) Decision-making under great uncertainty: environmental management in an era of global change. Trends in Ecology \& Evolution, 26, 398-404.

This article is protected by copyright. All rights reserved 
Possingham, H.P., Ball, I. \& Andelman, S. (2000) Mathematical methods for identifying representative reserve networks. In: Quantitative Methods for Conservation Biology. (Ed^Eds S. Ferson \& M.A. Burgman). Springer-Verlag, New York.

Power, M.E., Sun, A., Parker, G., Dietrich, W.E. \& Wootton, J.T. (1995) Hydraulic food-chain models. Bioscience, 45, 159-167.

Rastetter, E.B., Aber, J.D., Peters, D.P.C., Ojima, D.S. \& Burke, I.C. (2003) Using mechanistic models to scale ecological processes across space and time. Bioscience, 53, 68-76.

Regan, H.M., Colyvan, M. \& Burgman, M.A. (2002) A taxonomy and treatment of uncertainty for ecology and conservation biology. Ecological Applications, 12, 618-628.

Reid, M.A. \& Quinn, G.P. (2004) Hydrologic regime and macrophyte assemblages in temporary floodplain wetlands: Implications for detecting responses to environmental water allocations. Wetlands, 24, 586-599.

Russo, J.E. \& Shoemaker, P.J.H. (2001) Winning Decisions: Getting it Right the First Time, Currency Doubleday, New York.

Schindler, D.E. \& Hilborn, R. (2015) Prediction, precaution, and policy under global change. Science, $347,953-954$.

Seneviratne, S.I., Donat, M.G., Mueller, B. \& Alexander, L.V. (2014) No pause in the increase of hot temperature extremes. Nature Climate Change, 4, 161-163.

Shea, K. (1998) Management of populations in conservation, harvesting and control. Trends in Ecology \& Evolution, 13, 371-375.

Shenton, W., Bond, N.R., Yen, J.D.L. \& Mac Nally, R. (2012) Putting the "Ecology" into Environmental Flows: Ecological Dynamics and Demographic Modelling. Environmental Management, 50, 1 10.

Souchon, Y., Sabaton, C., Deibel, R., Reiser, D., Kershner, J., Gard, M., Katopodis, C., Leonard, P., Poff, N.L., Miller, W.J. \& Lamb, B.L. (2008) Detecting biological responses to flow management: Missed opportunities; Future directions. River Research and Applications, 24, 506-518.

Sousa, P.M., Trigo, R.M., Aizpurua, P., Nieto, R., Gimeno, L. \& Garcia-Herrera, R. (2011) Trends and extremes of drought indices throughout the 20th century in the Mediterranean. Natural Hazards and Earth System Sciences, 11, 33-51.

Spring, D.A., Croft, L., Bond, N.R., Cunningham, S.C., Mac Nally, R. \& Kompas, T. (submitted) Institutional impediments to conservation of freshwater dependent ecosystems. under review.

Stewardson, M.J. \& Skinner, D. (In press) Evaluating use of environmental flows to aerate streams by modelling the counterfactual case. Environmental Management. 
Stewart-Oaten, A. (2008) Chance and randomness in design versus model-based approaches to impact assessment: comments on Bulleri et al., (2007). Environmental Conservation, 35, 810.

Stewart-Oaten, A. \& Bence, J.R. (2001) Temporal and spatial variation in environmental impact assessment. Ecological Monographs, 71, 305-339.

Stewart-Oaten, A., Bence, J.R. \& Osenberg, C.W. (1992) Assessing effects of unreplicated perturbations: No simple solutions. Ecology, 73, 1396-1404.

Stoffels, R.J. (2015) Physiological trade-offs along a fast-slow lifestyle continuum in fishes: What do they tell us about resistance and resilience to hypoxia? Plos One, 10, e0130303.

Stoffels, R.J., Clarke, K.R., Rehwinkel, R.A. \& Mccarthy, B.J. (2014) Response of a floodplain fish community to river-floodplain connectivity: natural versus managed reconnection. Canadian Journal of Fisheries and Aquatic Sciences, 71, 236-245.

Sutherland, W.J., Bellingan, L., Bellingham, J.R., Blackstock, J.J., Bloomfield, R.M., Bravo, M., Cadman, V.M., Cleevely, D.D., Clements, A., Cohen, A.S., Cope, D.R., Daemmrich, A.A., Devecchi, C., Anadon, L.D., Denegri, S., Doubleday, R., Dusic, N.R., Evans, R.J., Feng, W.Y., Godfray, H.C.J., Harris, P., Hartley, S.E., Hester, A.J., Holmes, J., Hughes, A., Hulme, M., Irwin, C., Jennings, R.C., Kass, G.S., Littlejohns, P., Marteau, T.M., Mckee, G., Millstone, E.P., Nuttall, W.J., Owens, S., Parker, M.M., Pearson, S., Petts, J., Ploszek, R., Pullin, A.S., Reid, G., Richards, K.S., Robinson, J.G., Shaxson, L., Sierra, L., Smith, B.G., Spiegelhalter, D.J., Stilgoe, J., Stirling, A., Tyler, C.P., Winickoff, D.E. \& Zimmern, R.L. (2012) A Collaboratively-Derived Science-Policy Research Agenda. Plos One, 7.

Sutherland, W.J., Fleishman, E., Mascia, M.B., Pretty, J. \& Rudd, M.A. (2011) Methods for collaboratively identifying research priorities and emerging issues in science and policy. Methods in Ecology and Evolution, 2, 238-247.

Sutherland, W.J. \& Woodroof, H.J. (2009) The need for environmental horizon scanning. Trends in Ecology \& Evolution, 24, 523-527.

Urban, D.L. (2005) Modeling ecological processes across scales. Ecology, 86, 1996-2006.

Vorosmarty, C.J., Green, P., Salisbury, J. \& Lammers, R.B. (2000) Global water resources: Vulnerability from climate change and population growth. Science, 289, 284-288.

Walker, K.F. \& Thoms, M.C. (1993) Environmental effects of flow reguation on the lower River Murray, Australia. Regulated Rivers-Research \& Management, 8, 103-119.

Walters, C. (1997) Challenges in adaptive management of riparian and coastal ecosystems. Ecology and Society, 1, 1-19.

This article is protected by copyright. All rights reserved 
Walters, C.J. \& Holling, C.S. (1990) Large-scale management experiments and learning by doing. Ecology, 71, 2060-2068.

Webb, J.A., De Little, S.C., Miller, K.A. \& Stewardson, M.J. (In press) Quantifying and predicting the benefits of environmental flows: combining large scale monitoring data and expert knowledge within hierarchical Bayesian models. Freshwater Biology.

Webb, J.A., Stewardson, M.J., Chee, Y.E., Schreiber, E.S.G., Sharpe, A.K. \& Jensz, M.C. (2010) Negotiating the turbulent boundary: the challenges of building a science-management collaboration for landscape-scale monitoring of environmental flows. Marine and Freshwater Research, 61, 798-807.

Wenger, S.J. \& Olden, J.D. (2012) Assessing transferability of ecological models: an underappreciated aspect of statistical validation. Methods in Ecology and Evolution, 3, 260-267.

Westgate, M.J., Likens, G.E. \& Lindenmayer, D.B. (2013) Adaptive management of biological systems: A review. Biological Conservation, 158, 128-139.

Whitworth, K.L., Baldwin, D.S. \& Kerr, J.L. (2012) Drought, floods and water quality: Drivers of a severe hypoxic blackwater event in a major river system (the southern Murray-Darling Basin, Australia). Journal of Hydrology, 450, 190-198.

Wolkovich, E.M., Cook, B.I., Mclauchlan, K.K. \& Davies, T.J. (2014) Temporal ecology in the Anthropocene. Ecology Letters, 17, 1365-1379.

Yang, W. (2011) A multi-objective optimization approach to allocate environmental flows to the artificially restored wetlands of China's Yellow River Delta. Ecological Modelling, 222, 261267.

Yokota, F. \& Thompson, K.M. (2004) Value of information analysis in environmental health risk management decisions: Past, present, and future. Risk Analysis, 24, 635-650.

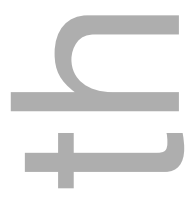

Table 1. Descriptions of the five stakeholder groups identified by Conroy and Peterson (2013). Stakeholders in riverine flow management are persons or organisations with a vested interest in the rationale for, and outcomes of, flow management decisions.

Consumers Members of the public that use freshwater resources either consumptively or nonconsumptively. The financial position of individuals in this group is not directly affected by flow management decisions. Examples include anglers, birdwatchers, hunters, boaters, campers and tourists to riverside communities affected by the aesthetics of river-floodplain 


\begin{tabular}{ll}
\hline & ecosystems. \\
\hline $\begin{array}{l}\text { Non-government } \\
\text { organisations (NGOs) }\end{array}$ & $\begin{array}{l}\text { Organisations that advocate for the wise use of environmental water that are not part of any } \\
\text { governmental organisation and are generally non-profit. Examples include International } \\
\text { Union for the Conservation of Nature and Natural Resources (IUCN), the Murray-Darling } \\
\text { Basin's Water Trust Alliance, and hunting and fishing lobby groups. }\end{array}$ \\
\hline Government water & $\begin{array}{l}\text { Regional, state and federal water management agencies responsible for managing riverine } \\
\text { flows within their legally-mandated jurisdiction. In Australia, from federal down to regional, } \\
\text { examples include Commonwealth Environmental Water Office, NSW Office of Environment } \\
\text { and Heritage, and regional catchment management authorities. }\end{array}$ \\
\hline Political & $\begin{array}{l}\text { Elected representatives of regional, state and federal governments. Political stakeholders in } \\
\text { flow management can have a strong impact on the activities of other stakeholder groups, } \\
\text { particularly water management agencies. }\end{array}$ \\
\hline Businesses and landholders whose financial position is affected by flow management \\
decisions. Examples include power-generation companies, irrigators, floodplain landholders, \\
regional councils, riverine tourism businesses, and businesses that supply goods and services \\
to these groups.
\end{tabular}

Table 2. A two-way table explaining the need for scientifically-defensible decision-making processes when making decisions in the face of uncertainty. Adapted from Russo \& Shoemaker (2001).

Good decision process

Desirable
outcome $\begin{gathered}\text { "Dumb luck;" we cannot explain to } \\ \text { stakeholders why a good outcome was } \\ \text { achieved, and don't know what to expect next } \\ \text { time. }\end{gathered}$

Table 3. Six guidelines for effective monitoring and evaluation of flows, based on a synthesis of the recommendations of Lovett et al. (2007), Nichols and Williams (2006), Walters (1997) and 
Lindenmayer and Likens (2009; 2010), as well as our own experience with design and implementation of such projects in the Murray-Darling Basin.

\section{Set clear monitoring objectives that explicitly guide sampling design, in light of:}

- Management objectives and decision options. By designing a monitoring program around management objectives and decisions, we give ourselves the best chance of ensuring the monitoring project facilitates robust reporting of outcomes to stakeholder groups, and reducing uncertainty about ecological responses to the management decisions being made.

- $\quad$ Theoretical/conceptual frameworks. Reference to the latest theory may be a means to at least three ends: (1) compelling research questions, hence improved advocacy from scientific stakeholders; (2) improved efficiency at the design phase of a monitoring project (e.g. why develop numerous conceptual models to guide specific questions/hypotheses if there are peer-reviewed, published frameworks that already fulfil the purpose?); (3) more efficient reduction in structural uncertainty, through ensuring research questions are novel and extend our understanding.

- Spatial and temporal scale of response. Water managers and scientists must have a shared understanding of the likely spatial and temporal scales of response expected from each indicator. If managers and scientists share this understanding, they will then share expectations concerning, for example, the challenges of linking flow decisions and outcomes at large spatial scales, and the time required to report against certain management objectives associated with 'slow' ecological response variables.

- A clear plan for outputs and analysis. Is the aim to output new knowledge within published papers and reports, or to estimate parameters of models that facilitate analysis and forecasting? (Arguably, a good monitoring project would do both.) The sampling/experimental design must be developed in light of the data requirements (including precision and accuracy) and assumptions of the models they are intended for. Aim for quantitative, continuous relations between flows and ecological response, as such relations allow calculation of effect size and direction as continuous functions of specific flow variables. Consideration may need to be given to the problem of inference in unreplicated, perturbation studies.

2. Involve key stakeholders in the setting of objectives, at project inception. Prior to development of the monitoring and evaluation plan, stakeholders that can significantly influence the success of the plan must be involved. Failure to do so can greatly erode the quality and success of monitoring and evaluation.

\section{Carefully consider the human and financial resources required to meet monitoring objectives. Set monitoring and} evaluation objectives in light of financial constraints. Don't spread financial resources too thinly by trying to monitor too much. Factor in the full cost of meeting all monitoring and evaluation objectives, including data management, frequent expert analysis of ecological dynamics, and communication of results to stakeholders; often projects allocate insufficient funds to the "evaluation' half of monitoring and evaluation. Given the nature of monitoring objectives, long-term (>10 y) funding-hence very strong science-management partnerships-is usually required to meet objectives.

4. Include peer review. For quality assurance, the monitoring plan should be subject to expert review, before it is implemented.

5. Implement adaptive monitoring. Regularly check whether the data are suitable for their intended purpose, particularly early in the project's development. Make adjustments to sampling methods if necessary, without compromising ability to meet core evaluation objectives of the project in the long-term. If, through hypothesis-testing, certain aspects of structural uncertainty are sufficiently reduced, then certain components of the monitoring project can be changed to tackle other aspects of structural uncertainty. Keep the monitoring interesting and relevant to scientific and management stakeholder groups. 


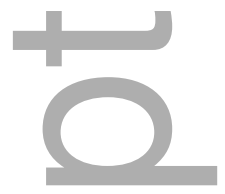

\section{Figure legends}

Fig. 1. Types of uncertainty most relevant to flow management (adapted from Conroy and Peterson (2013) and Regan et al. (2002)). To illustrate the types of uncertainty we present a hypothetical example of the influence of single flow management decision (long or short floodplain inundation) on the germination and recruitment outcomes of a riparian tree species. (a) Environmental uncertainty refers to the influence of background environmental variables that are random in nature (e.g. climatic conditions), are beyond the control of the decision maker, but affect the outcome of a flow intervention. (b) Statistical uncertainty arises as a consequence of our inability to make perfect scientific measurements of ecological systems. Measurement error generates imprecision in our estimate. Systematic error occurs when our samples are biased. (c) Structural uncertainty refers to uncertainty in our understanding of the basic relationships among components within our model of flow-response (be that model conceptual or mathematical).

Fig. 2. The decisions that water managers need to make vary depending on the spatial/jurisdictional and temporal scales of management. Here we present 10 questions concerning how water should be allocated to floodplains of the Murray-Darling Basin, Australia. On the right, the spatial scale of jurisdiction of four key management agencies are presented; there is only partial overlap in the types of decisions these agencies must make. The questions in this table are based on our interpretation of the Watering Plan (MDBA 2014) and our own experience in working with flow managers at different jurisdictional scales.




(a) Environmental uncertainty



(b) Statistical uncertainty

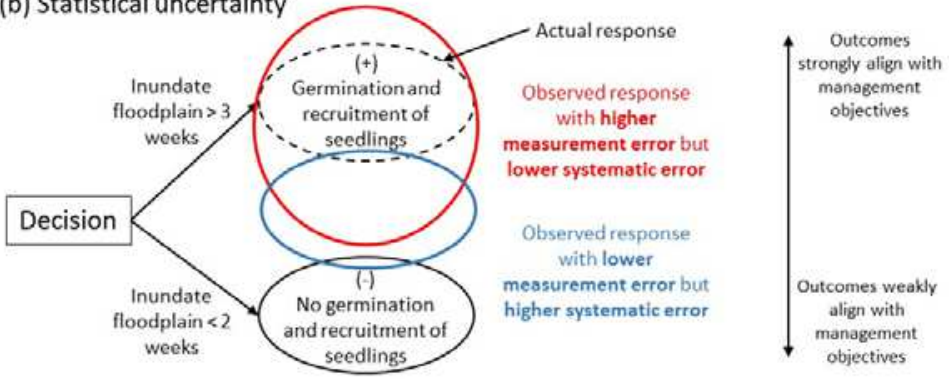

(c) Structural uncertainty

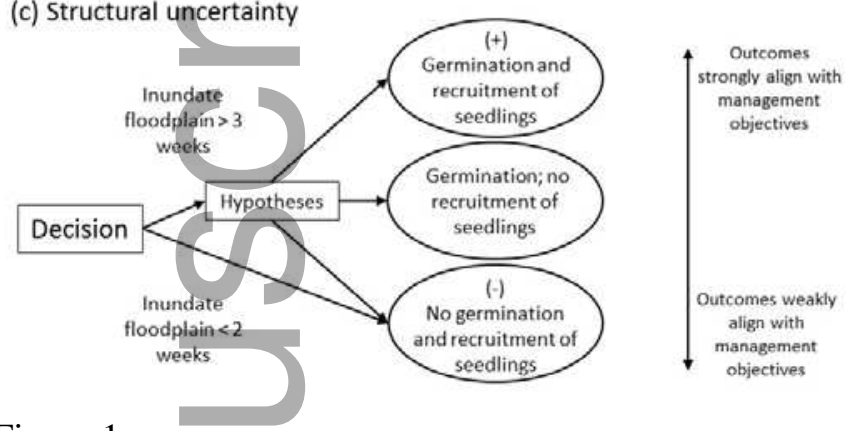

Figure 1.
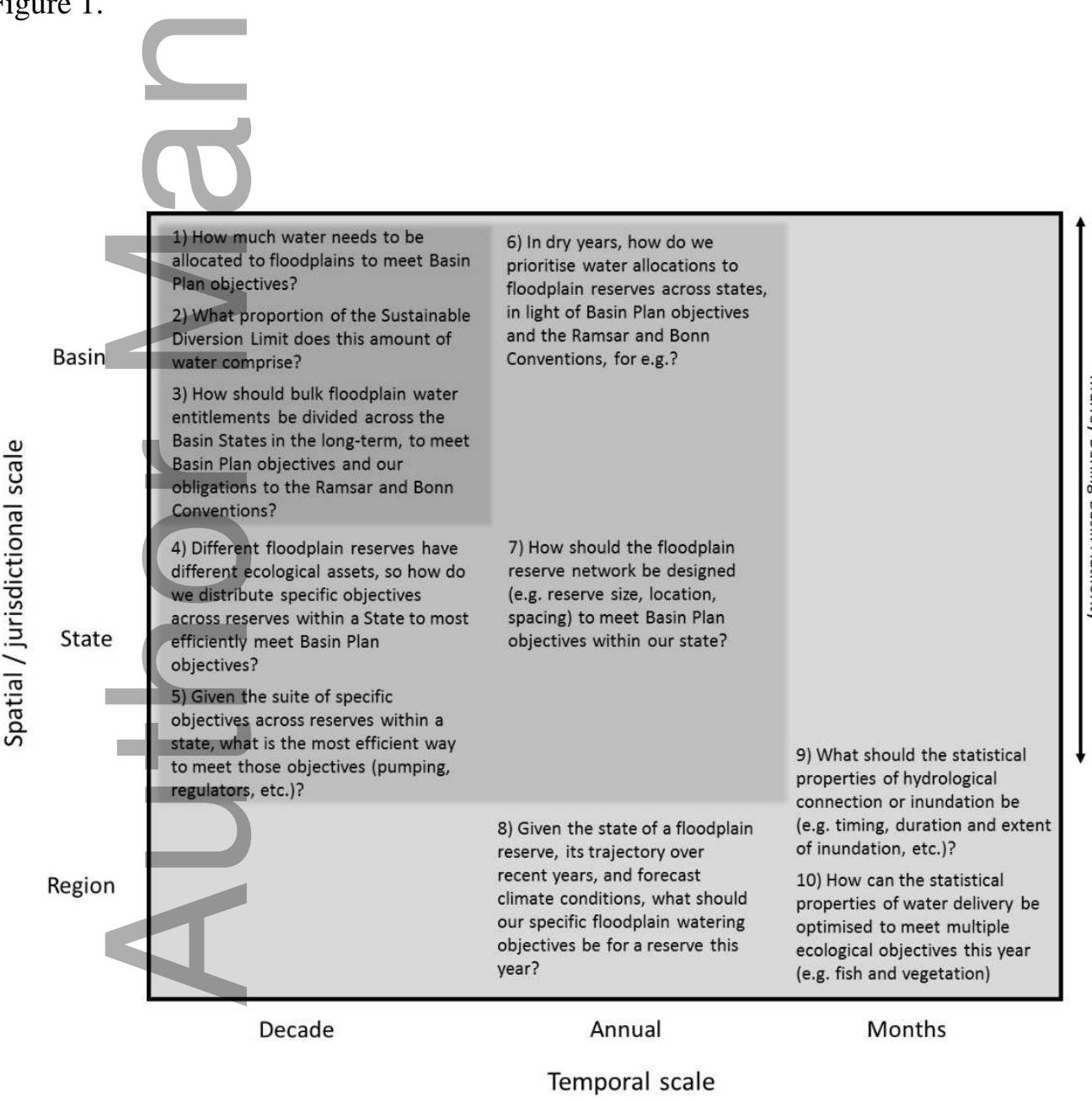

Figure 2. 
(a) Emvironmentaf untertainty

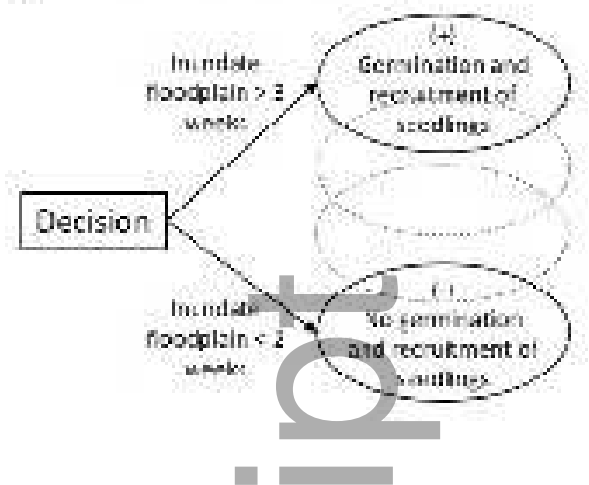

(b) 5 Latisticel uncer Lairtzy



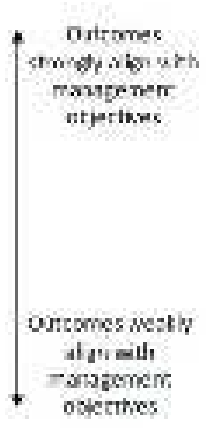

(c) S:ructural uncertainty
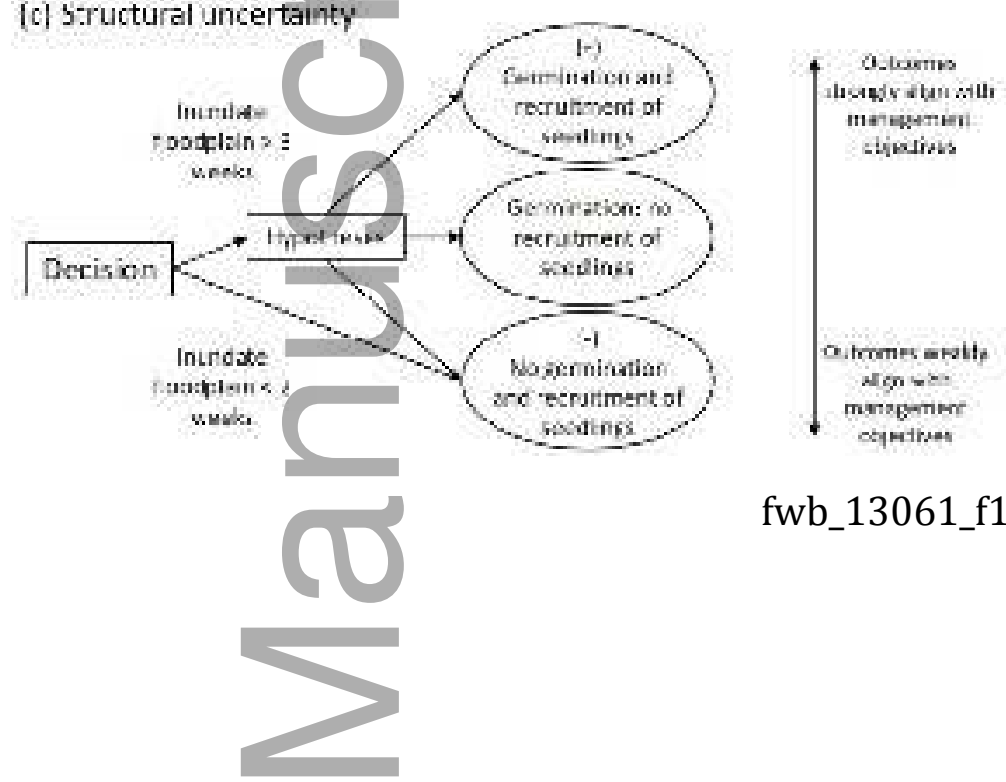

fwb_13061_f1.jpg

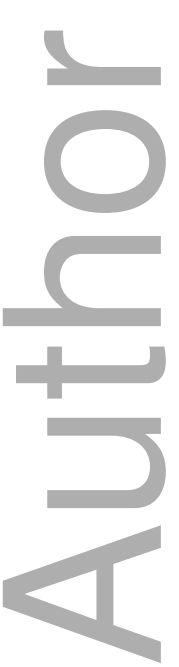

This article is protected by copyright. All rights reserved 


\section{University Library}

\section{- M M N E R VA A gateway to Melbourne's research publications}

Minerva Access is the Institutional Repository of The University of Melbourne

Author/s:

Stoffels, RJ;Bond, NR;Nicol, S

Title:

Science to support the management of riverine flows

Date:

2018-08-01

Citation:

Stoffels, R. J., Bond, N. R. \& Nicol, S. (2018). Science to support the management of riverine flows. FRESHWATER BIOLOGY, 63 (8), pp.996-1010. https://doi.org/10.1111/fwb.13061.

Persistent Link:

http://hdl.handle.net/11343/285176 